\title{
LIXIVIAÇÃO SELETIVA DE COBRE UTILIZANDO GLICINA EM SOLUÇÕES ALCALINAS*
}

Resumo

Juan Enrique Alvarez Ogusko ${ }^{1}$ Rosario Belen Juyo Salazar ${ }^{2}$ Paula Aliprandini ${ }^{3}$ Jorge Alberto Soares Tenório ${ }^{4}$ Denise Crocce Romano Espinosa ${ }^{5}$

Rotas hidrometalúrgicas para o beneficiamento do minério de cobre vem sendo estudadas a fim de substituir o processo tradicional por pirometalurgia. No entanto, 0 uso de soluções lixiviantes como o ácido sulfúrico e a amônia são considerados ambientalmente desfavoráveis ao processo e descarte. Além disso, durante a lixiviação do cobre também ocorre a lixiviação do ferro. O uso de glicina como agente lixiviante é uma alternativa de baixo impacto ambiental já que é um aminoácido capaz de ser metabolizado por organismos vivos. Na lixiviação, a glicina apresenta a capacidade de formar um complexo quelante apenas com o íon $\mathrm{Cu}^{2+}$. Esse trabalho buscou avaliar a capacidade de lixiviação de um minério de cobre concentrado proveniente do Peru. Para isso, três concentrações de glicina em meio aquoso foram avaliadas nas temperaturas de $25^{\circ} \mathrm{C}$ (48 horas de contato) e $60^{\circ} \mathrm{C}$ (duas horas de contato). $\mathrm{O} \mathrm{pH}$ da solução foi mantido entre 10,5 e 11 com adição de hidróxido de sódio. Foi possível lixiviar acima de $30 \%$ do cobre usando $0,8 \mathrm{M}$ de glicina na solução e em ambas as temperaturas de estudo. Além disso, a lixiviação do ferro ficou abaixo de $0,6 \%$ mostrando a seletividade da glicina para o cobre durante a lixiviação.

Palavras-chave: Minério de cobre; Hidrometalurgia; Lixiviação alcalina; Glicina.

\section{THE SELECTIVE LEACHING OF COPPER USING GLYCINE IN ALKALINE SOLUTIONS}

\section{Abstract}

Ore copper are usually treated by pyrometallurgical methods. However, other methods have been investigated to replace the traditional process. Hydrometallurgy processing is an alternative route for copper ore treatment. The copper ore can be leached with sulfuric acid or ammonia, but disposing of waste has environmental impacts. Besides copper, iron present in the ore are also leached. Leaching reactions of copper with glycine are safe for environment. Glycine is an amino acid and it is synthesized by living organisms. Glycine combines with the copper ion to form a chelate complex during the leaching process. The aim of this study was to investigate the effect of glycine as a leaching agent. The copper ore used in this study was obtained from Peru. Experimental solutions of glycine with different concentrations were prepared in aqueous media. The effect of two temperatures was evaluated: $25^{\circ} \mathrm{C}$ (contact time of 48 hours) and $60^{\circ} \mathrm{C}$ (contact time of two hours). In order to keep the $\mathrm{pH}$ between 10.5 and 11, sodium hydroxide was added. The results showed that leaching of copper corresponded to $30 \%$ in presence of $0.8 \mathrm{M}$ glycine for both temperatures. In addition, the percentage of iron in solution was less than $0.6 \%$. Copper was selectively leached using glycine.

Keywords: Copper ore; Hydrometallurgy; Alkaline leaching; Glycine.

Estudante de Engenharia Química, Universidad Nacional de San Agustín, Arequipa, Arequipa, Peru.

2 Bacharel em Química, Universidad Nacional de San Agustín, Arequipa, Arequipa, Peru.

3 Engenheira de Materiais, Mestre em Ciências, doutoranda do Departamento de Engenharia Química,

Escola Politécnica da Universidade de São Paulo, São Paulo, São Paulo, Brasil.

4 Engenheiro Metalurgista, Doutor em Engenharia Metalúrgica, Professor titular, Departamento de Engenharia Química, Escola Politécnica da Universidade de São Paulo, São Paulo, São Paulo, Brasil.

5 Engenheira Metalurgista, Doutora em Engenharia metalúrgica, Professora associada, Departamento de Engenharia Química, Escola Politécnica da Universidade de São Paulo, São Paulo, São Paulo, Brasil. 


\section{INTRODUÇÃO}

O minério de cobre é composto por diferentes compostos sulfetados como calcopirita $\left(\mathrm{CuFeS}_{2}\right)$ calcocita $\left(\mathrm{Cu}_{2} \mathrm{~S}\right)$, bornita $\left(\mathrm{Cu}_{5} \mathrm{FeS}_{4}\right)$, tetraedrita $\left(\mathrm{Cu}_{12} \mathrm{Sb}_{4} \mathrm{~S}_{13}\right)$ e enargita $\left(\mathrm{Cu}_{3} \mathrm{AsS}_{4}\right)$, além de outros tipos como a pirita $\left(\mathrm{FeS}_{2}\right)[1,2]$.

O beneficiamento tradicional do minério de cobre é feito através do processamento pirometalúrgico [2]. A produção de cobre por processamento hidrometalúrgico representa aproximadamente $20 \%$ da produção mundial do metal [3]. Para os processos hidrometalúrgicos pesquisas vem sendo desenvolvidas a fim de determinar rotas de lixiviação do minério capazes de substituir o processo pirometalúrgico. $\mathrm{Na}$ rota hidrometalúrgica o reagente usualmente usado pela indústria é o ácido sulfúrico $\left(\mathrm{H}_{2} \mathrm{SO}_{4}\right)$ [4]. Esse reagente tem a capacidade de lixiviar tanto o cobre quanto o ferro presentes no minério. Além do $\mathrm{H}_{2} \mathrm{SO}_{4}$, outros agentes lixiviantes podem ser usados como os cloretos, os sulfatos e a amônia $[5,6,7,8,9]$. $O$ uso de lixiviantes com amônia é questionável quanto a recuperação e reutilização dos reagentes. No uso de agentes ácidos, os volumes necessários, a baixa eficiência do processo e a reciclagem dos resíduos são os desafios vinculados com o processo de lixiviação.

O beneficiamento posterior à lixiviação segue por técnicas de precipitação e/ou eletrorecuperação dos metais presentes no lixiviado. Segundo Dreisinger [10], uma das desvantagens do processamento hidrometalúrgico é a perda de cobre por coprecipitação durante a remoção do ferro. Sendo assim, uma alternativa ao lixiviante ácido pode ser o uso de soluções contendo glicina. Esse processo já vem sendo estudado no beneficiamento de minérios de ouro e prata em meios alcalinos $[3,11,12]$.

A glicina é um aminoácido cuja fórmula química é $\mathrm{NH}_{2} \mathrm{CH}_{2} \mathrm{COOH}$. As vantagens do uso da glicina em soluções lixiviantes quando comparado com os outros meios diz respeito principalmente às questões ambientais. Por ser metabolizado por organismos vivos, o descarte torna-se de menor risco ambiental [3]. Na presença de cobre em solução, a glicina forma um complexo quelante com o metal conforme é proposto na Figura 1 [13].

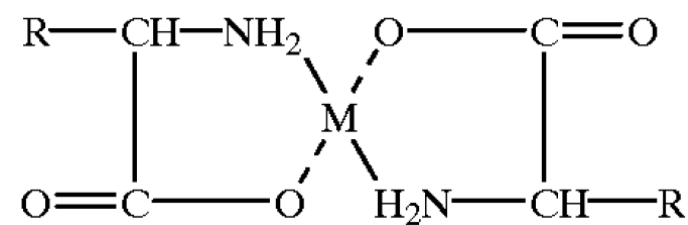

Figura 1. Complexo formado entre a glicina e os metais presentes em solução aquosa, onde $M$ pode ser substitído pelo íon $\mathrm{Cu}^{+2}[3,13]$.

No complexo sugerido, é possível substituir o $\mathrm{M}$ pelo íon metálico $\mathrm{Cu}^{+2}$.

Para esse estudo foi usada uma amostra de minério de cobre concentrado proveniente das minas de Yarabamba, Arequipa, no sul do Peru.

\section{MATERIAIS E MÉTODOS}

\subsection{Caracterização do minério}

A caracterização do minério foi feita a fim de verificar a morfologia e a quantidade relativa de ferro e cobre presente no concentrado do minério. Para isso, duas técnicas de caracterização foram utilizadas. 
A análise morfológica foi realizada no microscópio eletrônico de varredura com espectroscopia por dispersão de energia de raios $X$ (MEV/EDS).

Para a determinação da quantidade de cobre e ferro presentes no minério, foi inicialmente realizada a abertura da amostra com água régia (ácido nítrico e ácido clorídrico concentrados na relação 1:3). Uma amostra de três gramas foi colocada em contato com $42 \mathrm{~mL}$ de solução de água régia durnte 24 horas e em temperatura média de $60^{\circ} \mathrm{C}$. A análise da porcentagem de ferro e cobre foi determinada por espectroscopia de fluorescência de raios X por energia dispersiva (EDX) da solução final obtida.

\subsection{Ensaios de lixiviação}

Para o estudo da lixiviação do minério foram preparadas três soluções lixiviantes contendo glicina nas concentrações: $0,3 \mathrm{M}, 0,5 \mathrm{M}$ e $0,8 \mathrm{M}$. As três soluções foram preparadas em água deionizada. As amostras do minério de cobre foram colocadas em contato com as soluções de glicina em frascos tipo Erlenmeyer com capacidade de $250 \mathrm{~mL}$. Três gramas do minério foram usadas em cada contato com $125 \mathrm{~mL}$ de cada uma das soluções contendo glicina. $\mathrm{O} \mathrm{pH}$ das soluções parmeneceu na faixa $10,5 \leq \mathrm{pH} \leq 11$. Essa faixa de $\mathrm{pH}$ foi determinada com base na literatura $[3,12,14]$. $\mathrm{A}$ Figura 2 mostra o diagrama de potencial/pH para o sistema Cu-glicina em meio aquoso, temperatura $25^{\circ} \mathrm{C}$ e pressão atmosférica [14]. Nesse estudo, hidróxido de sódio foi usado para o ajuste do pH das soluções.

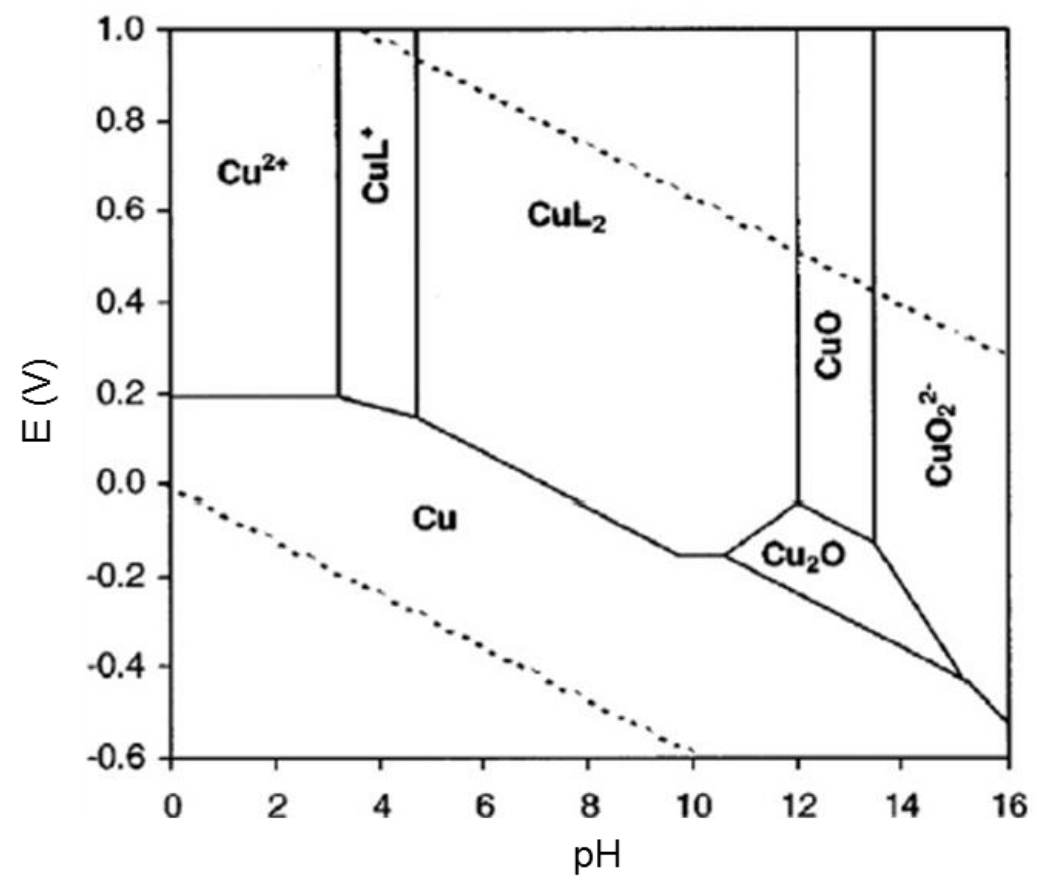

Figura 2. Diagrama do potencial x pH para o sistema cobre-glicina em meio aquoso na temperatura de $25^{\circ} \mathrm{C}$ e pressão atmosférica [14].

No diagrama, $L$ representa a glicina. É possível observar que na faixa de $\mathrm{pH}$ escolhido há a formação do complexo entre o íon metálico e o agente lixiviante.

As soluções foram mantidas sob agitação e em duas temperaturas de ensaio: $25^{\circ} \mathrm{C}$ e $60^{\circ} \mathrm{C}$. As soluções mantidas à $25^{\circ} \mathrm{C}$ permaneceram por 48 horas, enquanto que as aquecidas até $60^{\circ} \mathrm{C}$ por duas horas. A determinação dos tempos de contato também 
foi baseada em experimentos da literatura de maneira a garantir a lixiviação máxima do metal nas condições do estudo [3].

Após o processo de lixiviação, a solução foi filtrada e o sobrenadante analisado por espectroscopia de fluorescência de raios $X$ por energia dispersiva (EDX).

\section{RESULTADOS E DISCUSSÃO}

\subsection{Caracterização do minério}

A Figura 3 mostra a micrografia e o resultado da análise do EDS para a amostra do minério de cobre concentrado utilizado nesse estudo.
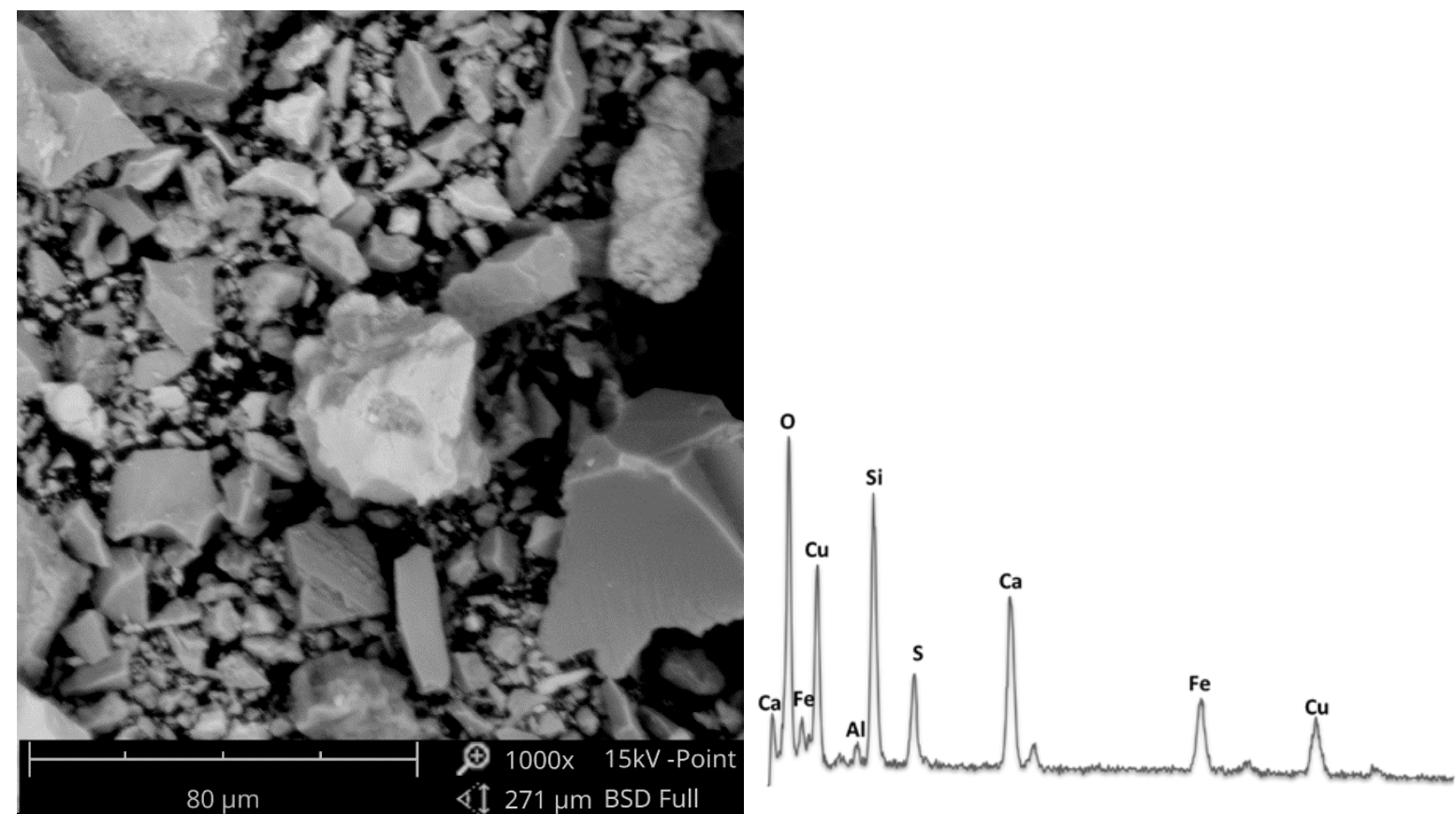

Figura 3. MEV/EDS do minério de cobre utilizado no estudo do lixiviante à base de glicina.

A partir da imagem do microscópio é possível observar que o concentrado do minério possui granulometria abaixo de $80 \mu \mathrm{m}$. O EDS é referente a área de análise e confirma a presença de cobre, ferro e enxofre, o que indica que o minério é composto por algum dos compostos característicos dos minérios de cobre como calcopirita, calcocita e bornita. Além disso, outros elementos como oxigênio, cálcio, alumínio e silício também são observados. Isso indica que o minério pode ter composição variada com a presença de mais de um tipo de composto.

A Tabela 1 mostra a porcentagem de cobre e ferro presentes no concentrado em estudo através da abertura da amostra usando água régia. As concentrações foram obtidas pela análise no EDX.

Tabela 1. Concentração de cobre e ferro presentes no minério de cobre.

\begin{tabular}{ccc} 
Elemento & Cu & Fe \\
\hline $\begin{array}{c}\text { Concentração } \\
(\% \mathbf{m} / \mathbf{m})\end{array}$ & 15 & 5 \\
\hline
\end{tabular}

A concentração de cobre é três vezes maior que a quantidade de ferro. A abertura da amostra serviu para prever o máximo de cada metal passível de lixiviação durante o processo de lixiviação usando soluções contendo glicina. 


\subsection{Ensaios de lixiviação}

A Figura 4 mostra o resultado da lixiviação de cobre e ferro para a temperatura de 25ํํ e variando a concentração de glicina presente na solução lixiviante.

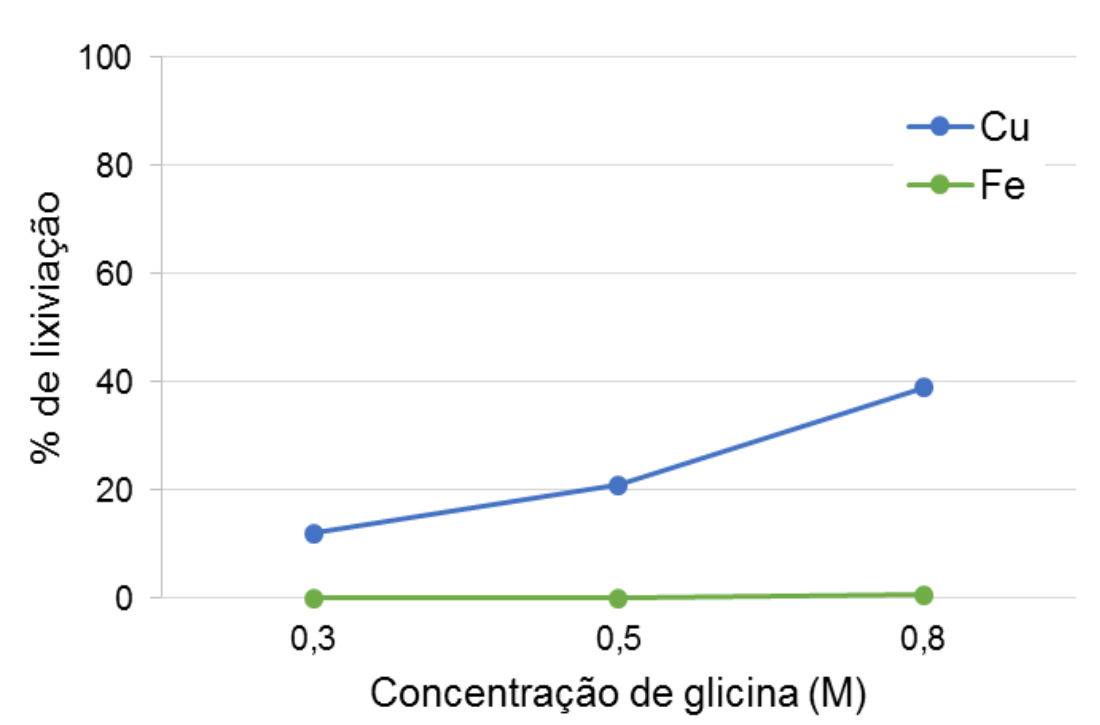

Figura 4. Lixiviação de cobre e ferro em função de concentração de glicina em $25^{\circ} \mathrm{C}$.

A lixiviação de cobre aumenta de $12 \%$ para $39 \%$ quando a quantidade de glicina no meio lixiviante também aumenta. Para o ferro, a lixiviação em todas as concentrações de glicina foi interior a $0,6 \%$. Isso mostra a seletividade de lixiviação da glicina para o cobre. Essa seletividade para o ion $\mathrm{Cu}^{+2}$ já tinha sido observada por Oraby [3] durante a lixiviação de um concentrado de cobre-ouro.

Ao avaliar a mudança de temperatura para $60^{\circ} \mathrm{C}$, a Figura 5 mostra quantidade de cobre lixiviado em comparação com o estudo a 25ํ․

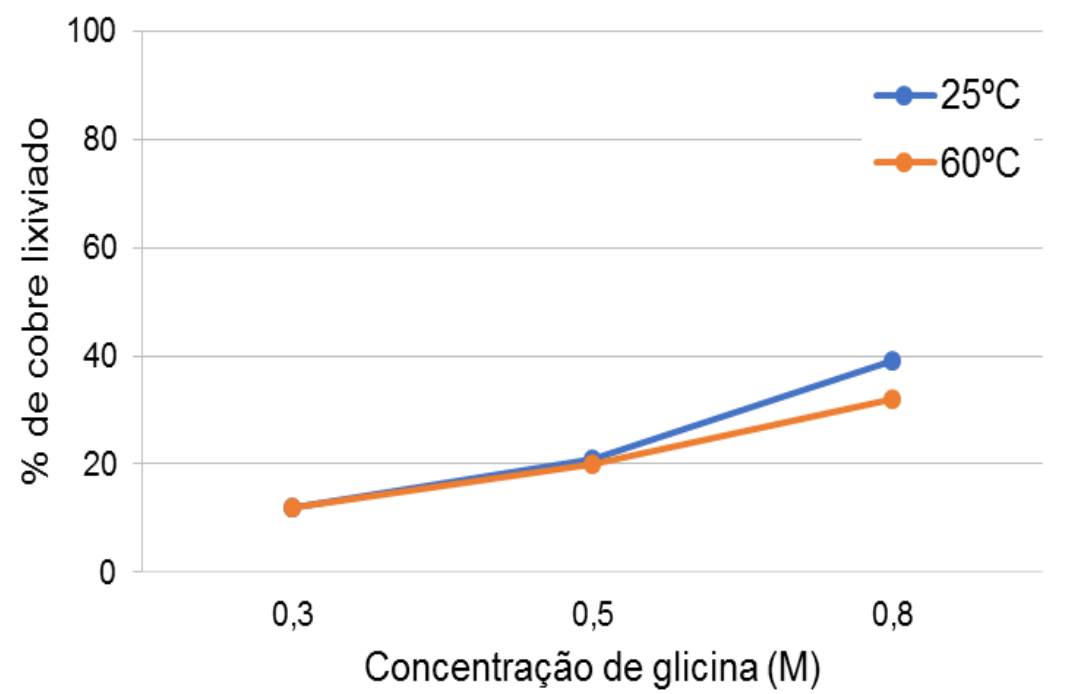

Figura 5. Comparativo entre a lixiviação de cobre em diferentes concentrações de glicina e em $25^{\circ} \mathrm{C}$ e $60^{\circ} \mathrm{C}$. 
A lixiviação do ferro foi inferior a $0,6 \%$, assim como em $25^{\circ} \mathrm{C}$. A partir dos resultados de alteração de temperatura é possível observar o comportamento semelhante de lixiviação com o aumento da concentração de glicina. Em concentrações de 0,3M e $0,5 \mathrm{M}$ os resultados de lixiviação foram os mesmos (aproximadamente $12 \%$ e $20 \%$, respectivamente). Para a concentração de glicina igual a $0,8 \mathrm{M}$ observou-se que a lixiviação de cobre foi inferior para a temperatura de $60^{\circ} \mathrm{C}$. No entanto, em ambas as temperaturas a lixiviação obtida do metal foi superior a $30 \%$.

Outro ponto do estudo se refere ao fato de que, com o aumento da temperatura, menos tempo de contato entre o minério e o agente lixiviante é necessário para que ocorra a mesma quantidade de cobre lixiviado.

Além disso, é importante destacar que, ao contrário das lixiviações tradicionais utilizando agentes lixiviantes à base de ácidos, a lixiviação com glicina se mostrou seletiva para o cobre, não havendo lixiviação significativa de ferro.

\section{CONCLUSÃO}

A partir dos resultados obtidos pode-se concluir que:

- O concentrado do minério é composto por partículas menores do que 80 $\mu \mathrm{m}$.

- A composição do minério apresenta os elementos cobre, ferro e enxofre, que são característicos dos compostos que tradicionalmente compõe os minérios de cobre. Além dos elementos citados, outros foram determinados pelo EDS, indicando que o minério pode ter composição variada.

- A lixiviação do cobre variou de $12 \%$ para $39 \%$ quando a concentração de glicina na solução lixiviante variou de $0,3 \mathrm{M}$ para $0,8 \mathrm{M}$ em temperatura de $25^{\circ} \mathrm{C}$.

- Ao aumentar a temperatura de ensaio para 60으 o comportamento da lixiviação do cobre permaneceu semelhante do que a $25^{\circ} \mathrm{C}$. Não houve aumento de lixiviação com o aumento da temperatura.

- Aumentando a temperatura de $25^{\circ} \mathrm{C}$ para $60^{\circ} \mathrm{C}$ foi possível obter resposta semelhante de lixiviação do cobre, porém com redução de 48 para duas horas de contato.

- Não houve lixiviação de ferro para nenhum estudo realizado acima de 0,6\%.

- O uso de glicina mostrou ser seletivo para a lixiviação do cobre presente no concentrado de minério de cobre.

\section{Agradecimentos}

À Universidade Nacional de San Agustin - Peru.

À Coordenação de Aperfeiçoamento de Pessoal de Nível Superior (CAPES) pelo suporte financeiro através da bolsa de doutorado.

À Fundação de Amparo à Pesquisa do Estado de São Paulo (FAPESP) pelo suporte financeiro através do projeto de pesquisa 2012/51871-9.

Os autores agradecem à Ana Carolina Fadel Dalsin pela ajuda nesse projeto.

\section{REFERÊNCIAS}

1 Porphírio NH, Barbosa MIM, Bertolino LC. Caracterização mineralógica de minérios - Parte I. In: Luz AB, Sampaio JA, França SCA. Tratamento de Minérios. Rio de Janeiro: CETEM/COPM; 2010.p.57-84. 
2 Dimitrijevic M, Kostov A, Tasic V, Milosevic N. Influence of pyrometallurgical production on the environment. Journal of Hazardous Materials. 2009; 164; 892899.

3 Orby EA, Eksteen JJ. The selective leaching of copper from a gold-copper concentrate in glycine solutions. Hydrometallurgy. 2014; 150; 14-19.

4 Sun X, Chen B, Yang X, Liu Y. Technological conditions and kinetics of leaching copper from complex copper oxide ore. Journal of Cetral South University. 2009; 16; 936-941.

$5 \quad$ Hirato T, Kinoshita M, Awakura Y, Majima H. The leaching of chalcopyrite with ferric chloride. Metallurgical Transactions B. 1986; 17; 19-28.

6 Al-Harahsheh M, Kingman S, Al-Harahsheh, A. Ferric chloride leaching of chalcopyrite: synergetic effect of $\mathrm{CuCl} 2$. Hydrometallurgy. 2008; 91; 89-97.

7 Miki $\mathrm{H}$, Nicol M. The dissolution of chalcopyrite in chloride solutions. IV. The kinetics of the auto-oxidation of copper(I). Hydrometallurgy. 2011; 105; 246-250.

8 Beckstead LW, Miller JD. Ammonia, oxidation leaching of chalcopyrite - surface deposit effects. Metallurgical Transactions B. 1977; 8; 31-38.

9 Munoz PB, Miller JD, Wadsworth ME. Reaction mechanism for the acid ferric sulfate leaching of chalcopyrite. Metallurgical Transactions B. 1979; 10; 149158.

10 Dreisinger D. Copper leaching from primary sulfides: options for biological and chemical extraction of copper. Hydrometallurgy. 2006; 83; 10-20.

11 Eksteen JJ, Oraby EA. The leaching and adsorption of gold using low concentration amino acids and hydrogen peroxide: Effect of catalytic ions, sulphide minerals and amino acid type. Minerals Engineering. 2015; 70; 36-42.

12 Oraby EA, Eksteen JJ. The leaching of gold, silver and their alloys in glycineperoxide solutions and their adsorption on carbon. Hydrometallurgy. 2015; 152; 199-203.

13 Ashmead CSD, Wheelwright LDC, Ericson MC, Pedersen KM. Composition and method for preparing amino acid chelate hydroxides free interfering ions. US 6,458,981 B1. 2002.

14 Tanda BC, Eksteen JJ, Oraby EA. An investigation into the leaching behavior of copper oxide minerals in aqueous alkaline glycine solutions. Hydrometallurgy. 2017; 167; 153-162. 